\title{
Job Satisfaction Among Academicians in Nepal: The Influence of Institutional Sector and Demographic Factors
}

\author{
Bal Ram Chapagain \\ Central Department of Management, Tribhuvan University, Kathmandu, Nepal
}

\begin{abstract}
Considering the importance of job satisfaction in teaching and the ongoing debate regarding the influence of various factors on job satisfaction, this study identifies the status of job satisfaction and examines the influence of institutional sector and demographic factors on job satisfaction among Nepalese academicians. The study sample comprised 156 academicians from different higherlevel educational institutions in Nepal, and the data were collected through structured questionnaires. Descriptive statistics, independent-samples t-test, and one-way ANOVA test were used to analyze the data. Results showed that Nepalese academicians are moderately satisfied with their job, in which intrinsic factors appear stronger than extrinsic factors. The findings also demonstrated that the institutional sector, in favor of public institutions, and academic qualification influence job satisfaction but gender, age, and teaching experience do not influence job satisfaction of academicians. Widespread sampling framework, allinclusive job satisfaction measures, and remarkable findings have made the study unique and potent.
\end{abstract}

Keywords: Academicians; demographic factors; institutional sector; job satisfaction; Nepal.

\section{Introduction}

\subsection{Background}

Although the concept of job satisfaction can be traced back to Taylor's scientific management movement, it is among the most researched topic in organizational behavior and human resource management even in recent years (Dhammika, 2017; Mendoza, 2019). Taylor (1911) considered the human being as an economic being, and money was believed to be the biggest reason for job satisfaction. However, existing literature on job satisfaction includes several dimensions beyond money and other forms of extrinsic rewards. Since then, Elton Mayo, Abraham Maslow, Frederick Herzberg, and many other scholars attempted to explain what factors make employees motivated, satisfied, and productive. According to Locke (1976), the common factors that determine the level of job satisfaction include the nature of work, pay, promotion, recognition, benefits, working conditions, and so on. In broad terms, both intrinsic, as well as extrinsic factors in the workplace, may trigger job satisfaction. However, recent literature has suggested that demographic factors such as gender, age, marital status, education, and job experience may also affect the level of job satisfaction (Din, Zaman \& Nawaz, 2010; Beyene \& Gituma, 2017).

Studies have produced different results regarding the status of job satisfaction and the influence of demographic variables on job satisfaction of employees. For instance, a recent study conducted at Oil and Natural Gas Corporation Limited (ONGC), India revealed that the employees were highly satisfied with their job and the demographic variables had a significant influence on job satisfaction (Ramachandran \& Shanthi, 2020). However, a study conducted among Lebanese banking sector managers revealed they were not adequately satisfied with their job

\footnotetext{
* Corresponding author.

E-mail address: balram.chapagain@cdm.tu.edu.np (Bal Ram Chapagain)
} 
particularly with extrinsic factors of job satisfaction (Tlaiss, 2013). The study also revealed demographic variables including marital status, age, and academic qualification do not have a significant impact on job satisfaction. In a similar vein, a study conducted in the Indian BPO industry showed that gender, marital status, education, age, and experience had no significant relationship with job satisfaction (Sengupta, 2011). Thus, it is obvious that the level of job satisfaction may vary across context, and researchers have not yet reached a consensus on whether the demographic variables influence job satisfaction.

The problem is further compounded since most of the existing studies have included only the extrinsic factors despite the equal or even higher importance of intrinsic factors in job satisfaction. Scholars argue that intrinsic factors such as work itself and opportunities to use abilities may be more important than extrinsic factors in determining the status of job satisfaction (Herzberg, 1987; Goetz, Campbell, Broge \& Dorfer, 2012). Moreover, there is a lack of studies regarding the status of job satisfaction and the influence of demographic factors on job satisfaction among academicians using an extensive sampling framework, particularly in the Nepalese context. As a result, higher-level educational institutions of Nepal are not able to make evidence-based decisions vis-à-vis various conditions of employment for their academic staff. If Nepalese academic institutions continue to rely on existing policies and practices, it may lead to sub-optimization of their valuable resources. Against this backdrop, the paper aims to identify the status of job satisfaction among Nepalese academicians and examine the influence of the institutional sector and demographic factors on job satisfaction.

The present research uses an extensive sampling framework by including the academicians of both the public and private sector academic institutions under major universities of Nepal and incorporates both extrinsic as well as intrinsic factors of job satisfaction. Hence the results provide valuable insights into human resource management decisions concerning the academic staff to create a win-win situation between the academicians and the academic institutions in Nepal.

The subsequent section starts with the review of literature along with the statement of hypotheses. This is followed by the methodology, and then results. Discussions have been done in the next section and, finally, the conclusion and implications of the study have been drawn.

\subsection{Literature Review and Statement of Hypotheses}

The extant literature on job satisfaction can be divided into two approaches: the situational approach and the dispositional approach. The situational approach believes that the degree of job satisfaction diff ers according to job characteristics and its environmental factors whereas the dispositional approach states that the extent of job satisfaction diff ers by individual human characteristics (Hackman \& Oldham, 1975; Herzberg, Mausner, \& Snyderman, 1959). Thus, job satisfaction can broadly be defined as an evaluative judgment of a job by a jobholder based on individual psychological, organizational, and environmental circumstances (Han \& Kakabadse, 2009). Though it is very difficult to prepare an exhaustive list of factors that trigger job satisfaction, they may be broadly divided into two types as extrinsic factors and intrinsic factors. If the job-surrounding environment, such as pay and working conditions, causes job satisfaction it is known as extrinsic job satisfaction. But, if job satisfaction is triggered by the attributes of the job itself, it is known as intrinsic job satisfaction (Buitendach \& Witte, 2005).

Previous studies conducted among academicians and other types of employees have shown different results regarding the status of their job satisfaction. The job satisfaction levels of academicians were found to be moderately high in Turkish universities in which intrinsic factors such as independence, variety, social status, moral values, and ability utilization were found to be stronger than extrinsic factors such as compensation, company policies \& practices, recognition, supervision, and working conditions (Toker, 2011). However, a study conducted among kindergarten teachers in Jordan revealed that the teachers experienced only a modest level of job satisfaction (Taleb, 2013). Among others, the institutional sector - public or private - was also found to influence the job satisfaction of people. A study conducted in the Indian context revealed that the public sector employees had high job satisfaction than private sector employees (Parchi \& Sajid, 2017). In contrast, a study conducted in Turkey demonstrated a high level of job satisfaction among private university academicians (Bas \& Ardic, 2002). Yet, some studies have reported no 
difference in the level of academicians' job satisfaction based on the sector in which they belong (Akhtar, Hashmi, \& Naqvi, 2010; Sultana, Sarker, \& Prodhan, 2017). Thus, considering the lack of overwhelming evidence concerning employee job satisfaction in favor of private or public sector organizations, the first hypothesis of the study is stated as:

$\mathrm{H}_{01}$ : The institutional sector - public or private - does not influence the job satisfaction of academicians.

Some previous studies have also reported that job satisfaction may be influenced by various demographic factors. A study conducted among teachers of Najran University, Saudi Arabia showed a moderate degree of job satisfaction with the significant influence of gender, teaching experience, and college type on the job satisfaction (Al-Smadi \& Qblan, 2015). The results revealed that the differences were in favor of males, scientific colleges, and more experienced faculty members. Likewise, a study conducted among government officers in Sri Lanka also revealed that most of the demographic variables including gender, experience, and education are significantly correlated with job satisfaction (Jayasena \& Weligamage, 2016).

However, some studies have reported mixed findings. An empirical investigation done among the academicians of Turkish universities revealed that age, job experience, and academic qualification were significantly related to job satisfaction whereas marital status and gender were not related to job satisfaction (Toker, 2011). In a similar vein, a recent study conducted among 150 employees of Nepalese financial institutions revealed that gender, job position, and age had significant influences on job satisfaction whereas marital status, job experience, and academic qualification did not influence on job satisfaction (Shrestha, 2018). Nevertheless, many studies have shown no significant influence of demographic factors, such as gender, age, experience, and academic qualification, on job satisfaction (Amarasena, Ajward \& Kaque, 2015; Rahnavard et al., 2018; Gunay, 2018).

Hence scholars have not yet reached a consensus on whether, and to what extent, the various demographic factors influence the job satisfaction of a jobholder. Such a lack of consensus regarding the influence of demographic factors on job satisfaction and the dearth of studies with an extensive sampling framework in the context of university-level academicians of Nepal creates an avenue for further investigation in this area. In this background, the next hypotheses of the study are stated as follows:

$\mathrm{H}_{02}$ : Gender does not influence the job satisfaction of academicians.

$\mathrm{H}_{03}$ : Age does not influence the job satisfaction of academicians.

$\mathrm{H}_{04}$ : Academic qualification does not influence the job satisfaction of academicians.

$\mathrm{H}_{05}$ : Teaching experience does not influence the job satisfaction of academicians.

\section{Methods}

This study is survey-based quantitative research. It employs descriptive and causal research designs. The population of this study consists of the academicians associated with four major universities of Nepal - Tribhuvan University, Kathmandu University, Pokhara University, and Purwanchal University - and the various private colleges affiliated to these universities. Stratified random sampling was used to ensure adequate representation of academicians associated with both public and private sector institutions under the selected universities. The total sample size of the study was 156. The distribution of the sample by institutional sector and demographic factors has been presented in Table 1. 
Table 1. Distribution of sample

\begin{tabular}{lll}
\hline Factors & Attribute & Percentage \\
\hline Institutional Sector & Public & 43.6 \\
& Private & 56.4 \\
\hline Gender & Male & 79.5 \\
& Female & 20.5 \\
\hline Age Group & Young (23-33) & 19.9 \\
& Middle-aged (34-44) & 47.4 \\
& Old (45-above) & 32.7 \\
\hline Academic Qualification & Masters & 46.8 \\
& M. Phil. & 34.0 \\
& Ph. D. & 19.2 \\
\hline Teaching Experience (in years) & Low (1-5) & 26.9 \\
& Medium (6-10) & 28.2 \\
& High (11-above) & 44.9 \\
\hline
\end{tabular}

The nature of data in this study is primary. The primary data were collected through structured questionnaires. Pretesting of the questionnaire was done before finalizing it. The finalized questionnaires were then distributed to the identified respondents. The questionnaires were anonymous and all the data were treated with the utmost confidentiality.

Various measures were taken to ensure the validity and reliability of the study. The survey questionnaire was adapted from past studies (Al-Rubaish, Rahim, Abumadini \& Wosornu, 2011; Vaijayanthi, Shreenivasan \& Roy, 2014) but finalized only after pretesting with experts in the field. Thus, content validity was established. Likewise, all the items within different constructs were adequately positively correlated with each other, thus this study also meets the criteria of convergent validity. To ensure reliability, first, objectives were formulated, and then hypotheses were stated after the extensive review of the literature. Second, all items measuring job satisfaction were designed on a five-point Likert scale rather than on a dichotomous scale. Finally, Inter-item consistency reliability statistics were obtained by calculating Cronbach's Alpha coefficients and the values of Cronbach's alpha were found to be above the acceptable level of 0.7 (Nunnally, 1978).

The data were analyzed by using percentage, mean, independent-samples t-test, and one-way analysis of variance (ANOVA) test. Before performing the t-test and one-way ANOVA test, the assumption of normality was tested using the Shapiro-Wilk test and the data were found to be normal. Note that, despite the availability of different statistical tests for normality, the Shapiro-Wilk test was used since it is generally recommended for samples up to 2000 (Garson, 2012). Post hoc analysis was also carried out, as needed, using the Gabriel procedure while performing a one-way ANOVA test.

\section{Results and Discussions}

To identify the status of job satisfaction among academicians in Nepal and examine the influence of demographic factors on their job satisfaction, the data were analyzed using SPSS 23.0. The results are presented and discussed in the following sections.

\subsection{Status of Job Satisfaction}

Table 2 shows the status of job satisfaction among academicians of Nepalese universities vis-à-vis ten items arranged under two constructs, namely, extrinsic job satisfaction and intrinsic job satisfaction. 
Table 2. Status of job satisfaction among academicians in Nepal

\begin{tabular}{|c|c|c|c|}
\hline \multirow[t]{2}{*}{ Job Satisfaction Items and Variables } & \multicolumn{3}{|c|}{ Mean } \\
\hline & Public Sector & Private Sector & Overall \\
\hline Salary or pay package & 4.09 & 3.50 & 3.76 \\
\hline Reward and recognition & 3.44 & 3.35 & 3.39 \\
\hline Working environment & 3.56 & 3.76 & 3.67 \\
\hline Opportunities for learning \& growth & 3.72 & 3.14 & 3.39 \\
\hline Job Security & 3.91 & 3.31 & 3.57 \\
\hline $\begin{array}{l}\text { Extrinsic Job Satisfaction } \\
\end{array}$ & 3.74 & 3.41 & 3.55 \\
\hline The Nature of the job itself & 4.04 & 3.78 & 3.90 \\
\hline Respect from the job & 3.88 & 3.81 & 3.84 \\
\hline The feeling of independence in the job & 3.5 & 3.34 & 3.41 \\
\hline Congruence with moral values & 3.97 & 3.53 & 3.72 \\
\hline Opportunities for the use of abilities & 4.12 & 3.57 & 3.81 \\
\hline Intrinsic Job Satisfaction & 3.90 & 3.60 & 3.73 \\
\hline Overall Job Satisfaction & 3.82 & 3.51 & 3.64 \\
\hline
\end{tabular}

Table 2 demonstrates that the job satisfaction level of academicians of Nepalese universities is moderately high. However, it appears that Nepalese academicians are more satisfied with intrinsic aspects than extrinsic aspects of job satisfaction. In particular, Nepalese academicians are highly satisfied with the nature of the job itself, respect from the job, and the opportunities for the use of abilities whereas they are relatively less satisfied with reward and recognition as well as the opportunities for learning \& growth from their institution.

This finding is consistent with the finding of a study conducted in the context of academicians of fifteen state universities in Sri Lanka (Amarasena et al., 2015). However, a study conducted among academicians of Najran University showed only a moderate level of job satisfaction (Al-Smadi \& Qblan, 2015). But, it is noteworthy to mention that the study indicated a higher level of intrinsic job satisfaction than extrinsic job satisfaction as in the case of this study. Relatively low level of extrinsic job satisfaction among academicians in the Nepalese context may be mainly ascribed to the fact that Nepal is among the least developed countries in the world and hence institutions generally have limited capacity to make necessary efforts for enhancing the extrinsic job satisfaction such as through adequate salary, rewards, facilities, and learning opportunities.

\subsection{Influence of Institutional Sector on Job Satisfaction}

Table 3 shows the t-test results of the differences in mean extrinsic, intrinsic, and overall job satisfaction scores for the public sector and private sector higher-education institutions in Nepal.

It is noteworthy to mention that academicians from the public sector institutions are more satisfied with their job compared to the academicians from the private sector as evident from the t-test results as shown in Table 3 .

As evident from the t-test results $(p<0.05)$ presented in Table 3, the first hypothesis of the study is rejected. That is, academicians from the public sector institutions have experienced significantly higher levels of extrinsic, intrinsic, and overall job satisfaction than the academicians from the private sector. It implies that the institutional sector, in favor of the public sector, influences the job satisfaction of academicians.

These findings are consistent with the findings of a study conducted among public and private sector educators in Greek (Tsigilis, Zachopoulou, \& Grammatikopoulos (2006). The study found that public sector educators were more satisfied with their job compared to their private sector counterparts. However, a study by Bas and Ardic (2002) revealed that academicians of private sector institutions were more satisfied with their job than the academicians of public sector institutions. 
Chapagain | Quantitative Economics and Management Studies (QEMS), 2020, 2(2): 94-104

Table 3. t-test results of job satisfaction by institutional sector

\begin{tabular}{lcccccc}
\hline \multirow{2}{*}{$\begin{array}{l}\text { Job Satisfaction } \\
\text { Variables }\end{array}$} & \multicolumn{2}{c}{ Mean } & \multicolumn{2}{c}{$\begin{array}{l}\text { Levene's Test for } \\
\text { Homogeneity of } \\
\text { Variances }\end{array}$} & t-test Results \\
\cline { 2 - 7 } & Public & Private & F-stat. & Sig. & t-value & Sig. \\
\hline $\begin{array}{l}\text { Extrinsic Job } \\
\text { Satisfaction }\end{array}$ & 3.74 & 3.41 & 2.496 & 0.116 & 3.552 & 0.001 \\
\hline $\begin{array}{l}\text { Intrinsic Job } \\
\text { Satisfaction }\end{array}$ & 3.90 & 3.60 & 7.338 & 0.008 & $(3.847)$ & $(0.000)$ \\
\hline $\begin{array}{l}\text { Overall Job } \\
\text { Satisfaction }\end{array}$ & 3.82 & 3.51 & 7.281 & 0.008 & $(4.580)$ & $(0.000)$ \\
\hline $\begin{array}{l}\text { Note: } \text { t-test results are kept without parentheses when equal variances are assumed and they are kept in the } \\
\text { parentheses when equal variances are not assumed. }\end{array}$ & & &
\end{tabular}

Among others, higher level of job satisfaction among public sector academicians in Nepal may be attributed to the socio-cultural context of the country. For instance, Nepal is characterized by long-term orientation and uncertainty avoidance culture (Gautam, Dick, Wanger, Upadhyay, \& Davis, 2005) where job security is highly valued by people. As a matter of fact, the condition of job security of is far higher in public academic institutions than in private institutions in the Nepalese context.

\subsection{Influence of Demographic Factors on Job Satisfaction}

\subsubsection{Influence of Gender on Job Satisfaction}

This section examines the influence of gender on job satisfaction by comparing the mean values for male and female academicians. Table 4 depicts the mean job satisfaction levels among academicians by gender and the t-tests for the difference between their means.

Table 4. t-test results of job satisfaction by gender

\begin{tabular}{lllllll}
\hline \multirow{2}{*}{ Job Satisfaction Variables } & Mean & \multicolumn{3}{l}{$\begin{array}{l}\text { Levene's Test for } \\
\text { Homogeneity of } \\
\text { Variances }\end{array}$} \\
\cline { 2 - 8 } & Male & Female & F-stat. & Sig. & t-value & Sig. \\
\hline Extrinsic Job Satisfaction & 3.51 & 3.70 & 1.057 & 0.306 & -1.588 & 0.114 \\
\hline Intrinsic Job Satisfaction & 3.74 & 3.71 & 5.731 & 0.018 & $(0.360)$ & $(0.720)$ \\
\hline Overall Job Satisfaction & 3.63 & 3.71 & 9.274 & 0.003 & $(-1.062)$ & $(0.292)$ \\
\hline
\end{tabular}

Note: $t$-test results are kept without parentheses when equal variances are assumed and they are kept in the

parentheses when equal variances are not assumed.

The mean values in Table 4 show that female academicians have experienced a higher level of extrinsic as well as overall job satisfaction whereas male academicians have experienced a higher level of intrinsic job satisfaction. To test the statistical significance of the influence of gender on job satisfaction, independent samples t-tests were conducted. The statistics in Table 4 show that the levels of extrinsic job satisfaction, intrinsic job satisfaction, and overall job satisfaction do not differ significantly for male and female academicians $(p>0.05)$. Thus, the second hypothesis cannot be rejected, that is, there is no adequate evidence to confirm that gender affects the job satisfaction of academicians.

\subsubsection{Influence of Age on Job Satisfaction}

This section examines the influence of age on job satisfaction by comparing their mean values for young, middleaged, and old-aged academicians of Nepalese higher-level educational institutions. Table 5 depicts the descriptive 
statistics of job satisfaction among academicians by age and the one-way ANOVA tests for differences between their means.

Table 5. One-way ANOVA results of job satisfaction by age

\begin{tabular}{|c|c|c|c|c|c|c|c|}
\hline \multirow[t]{2}{*}{$\begin{array}{l}\text { Job Satisfaction } \\
\text { (JS) Variables }\end{array}$} & \multicolumn{3}{|l|}{ Mean } & \multicolumn{2}{|c|}{$\begin{array}{l}\text { Levene's Test for } \\
\text { Homogeneity of } \\
\text { Variances }\end{array}$} & \multicolumn{2}{|c|}{$\begin{array}{l}\text { One-way ANOVA } \\
\text { Results }\end{array}$} \\
\hline & Young & M.-aged & Old & L-stat. & Sig. & F-value & Sig. \\
\hline Extrinsic JS & 3.45 & 3.52 & 3.65 & 0.919 & 0.401 & 1.245 & 0.291 \\
\hline Intrinsic JS & 3.68 & 3.80 & 3.67 & 0.287 & 0.751 & 1.088 & 0.339 \\
\hline Overall JS & 3.57 & 3.66 & 3.67 & 0.722 & 0.488 & 0.494 & 0.611 \\
\hline
\end{tabular}

The mean values in Table 5 show that the levels of extrinsic as well as overall job satisfaction tend to increase with the increase in the age of academicians whereas the level of intrinsic job satisfaction is high among middle-aged academicians compared to among young and old-aged academicians. However, the reported F-values show that young, middle-aged, and old teachers do not significantly differ in the levels of extrinsic, intrinsic, and overall job satisfaction $(p>0.05)$. Thus, the third hypothesis of the study cannot be rejected, that is, there is no sufficient evidence to ascertain that age affects the job satisfaction of academicians.

\subsubsection{Influence of Academic Qualification on Job Satisfaction}

This section examines the influence of academic qualification on job satisfaction by comparing the mean values for Masters, M.Phil., and Ph.D. degree holder academicians in Nepal. Table 6 depicts the descriptive statistics of job satisfaction among academicians of Nepalese universities by academic qualification and the one-way ANOVA tests for differences between their means.

Table 6. One-way ANOVA results of job satisfaction by academic qualification

\begin{tabular}{llllllll}
\hline \multirow{2}{*}{$\begin{array}{l}\text { Job Satisfaction } \\
\text { (JS) Variables }\end{array}$} & \multicolumn{3}{l}{ Mean } & \multicolumn{3}{c}{$\begin{array}{l}\text { Levene's Test for } \\
\text { Homogeneity of } \\
\text { Variances }\end{array}$} & \multicolumn{2}{c}{$\begin{array}{l}\text { One-way } \\
\text { ANOVA Results }\end{array}$} \\
\cline { 2 - 8 } & Mast. & M.Phil. & Ph.D. & L-stat. & Sig. & F-value & Sig. \\
\hline Extrinsic JS & 3.41 & 3.62 & 3.78 & 0.907 & 0.406 & 4.570 & 0.012 \\
\hline Intrinsic JS & 3.65 & 3.80 & 3.82 & 3.088 & 0.048 & 1.971 & 0.143 \\
\hline Overall JS & 3.53 & 3.71 & 3.80 & 2.619 & 0.076 & 4.551 & 0.012 \\
\hline
\end{tabular}

The mean values show that the levels of extrinsic job satisfaction, intrinsic job satisfaction, and overall job satisfaction increase with the increase in the academic qualification of academicians. However, the reported F-values show that intrinsic job satisfaction does not significantly differ among Masters, M.Phil., and Ph.D. degree holders ( $p>0.05)$. But, the levels of extrinsic job satisfaction and overall job satisfaction are significantly different across academic qualifications $(p<0.05)$. Thus, looking at the results vis-à-vis overall job satisfaction, the fourth hypothesis of the study is rejected which means that the academic qualification affects the job satisfaction of academicians.

To ascertain which pair(s) of groups causes the differences of means, post hoc analysis was conducted and the results are presented in Table 7.

The results presented in Table 7 demonstrate that the levels of extrinsic job satisfaction and overall job satisfaction of $\mathrm{Ph} . \mathrm{D}$. degree holders are significantly higher than that of Masters degree holders $(p<0.05)$. But, the differences in job satisfaction between Masters and M.Phil. as well as M.Phil. and Ph.D. degree holders are not statistically significant. 
Chapagain | Quantitative Economics and Management Studies (QEMS), 2020, 2(2): 94-104

Table 7. Post hoc analysis results of differences of means by academic qualification

\begin{tabular}{|c|c|c|c|}
\hline $\begin{array}{l}\text { Job Satisfaction } \\
\text { Variables }\end{array}$ & $\begin{array}{l}\text { Pair of Academic } \\
\text { Qualifications }\end{array}$ & Difference of Means & Sig. \\
\hline \multirow{3}{*}{$\begin{array}{l}\text { Extrinsic Job } \\
\text { Satisfaction }\end{array}$} & Masters and M.Phil. & -.20620 & 0.151 \\
\hline & Masters and Ph.D. & $-.36356^{*}$ & 0.012 \\
\hline & M.Phil. and Ph.D. & -.15736 & 0.557 \\
\hline \multirow[t]{3}{*}{ Overall Job Satisfaction } & Masters and M.Phil. & -.18033 & 0.088 \\
\hline & Masters and Ph.D. & $-.27046^{*}$ & 0.018 \\
\hline & M.Phil. and Ph.D. & -.09013 & 0.768 \\
\hline
\end{tabular}

\subsubsection{Influence of Teaching Experience on Job Satisfaction}

This section examines the influence of teaching experience on job satisfaction by comparing the mean values for low, medium, and highly experienced academicians of Nepalese universities. Table 8 depicts the mean scores of job satisfaction among academicians by teaching experience and the one-way ANOVA results for differences between their means.

Table 8. One-way ANOVA results of job satisfaction by teaching experience

\begin{tabular}{|c|c|c|c|c|c|c|c|}
\hline \multirow{2}{*}{$\begin{array}{l}\text { Job } \\
\text { Satisfaction } \\
\text { (JS) Variables }\end{array}$} & \multicolumn{3}{|c|}{ Mean } & \multicolumn{2}{|c|}{$\begin{array}{l}\text { Levene's Test for } \\
\text { Homogeneity of } \\
\text { Variances }\end{array}$} & \multicolumn{2}{|c|}{$\begin{array}{l}\text { One-way ANOVA } \\
\text { Results }\end{array}$} \\
\hline & Low & Medium & High & L-stat. & Sig. & F-value & Sig. \\
\hline Extrinsic JS & 3.52 & 3.39 & 3.67 & 0.052 & 0.949 & 3.208 & 0.043 \\
\hline Intrinsic JS & 3.73 & 3.72 & 3.74 & 0.381 & 0.684 & 0.013 & 0.987 \\
\hline Overall JS & 3.63 & 3.56 & 3.71 & 0.140 & 0.870 & 1.435 & 0.241 \\
\hline
\end{tabular}

The results show that the levels of extrinsic, intrinsic, and overall job satisfaction are low among medium experienced academicians. However, the reported F-values show that only extrinsic job satisfaction differs significantly among low, medium, and highly experienced academicians $(p<0.05)$. Thus, looking at the results vis-à-vis overall job satisfaction, the fifth hypothesis of the study cannot be rejected which means, there is no adequate evidence to confirm that teaching experience affects the job satisfaction of academicians.

Results presented above in Section 3.3 indicate that academic qualification influences job satisfaction whereas gender, age, and teaching experience do not have a significant influence on job satisfaction among academicians. As argued by Wright and Davis (2003), the positive influence of academic qualification on job satisfaction may be because the higher level of education \& training increases the job as well as psychological maturity, which ultimately triggers a higher level of job satisfaction. The results largely corroborate with the findings of Tarcan, Hikmet, Schooley, Top, and Tarcan (2017). They found no significant effect of demographic variables including gender, age, and marital status on job satisfaction. On the contrary, Al-Smadi and Oblan (2015) found that gender, teaching experience, and college type have a significant effect on job satisfaction. However, Toker (2011) has reported mixed findings. Among the various demographic factors age, academic qualification, and teaching experience were significantly related to job satisfaction whereas gender and marital status were not significantly related to job satisfaction. It is not uncommon to see differences across studies mainly due to the differences in the nature of the organizational sector being studied and the differences in socio-cultural and politico-economic contexts of countries.

\section{Conclusion and Implications}

The results demonstrate that the status of job satisfaction among the Nepalese academicians is moderately high, in which the level of intrinsic job satisfaction seems higher than extrinsic job satisfaction. The findings also confirm that 
the institutional sector, in favor of the public sector, influences the job satisfaction of academicians. It implies that the private sector academic institutions need to focus on improving the various aspects of job satisfaction if they want to take long-term advantages from the satisfied academicians who are supposed to be the most valuable assets for academic institutions. Notably, the results indicated that academic qualification positively influences the job satisfaction of academicians. Hence the Nepalese higher-level educational institutions need to give priority to the academic qualification of candidates than on particular gender, age group, or teaching experience in recruitment and selection decisions for creating a win-win situation between the institution and the academic staff.

This study has several implications pointing to interesting avenues for future research. First, future research studies may include a wide array of institutions beyond higher-level educational institutions, which would allow for comparison between them. Second, more demographic variables such as marital status (single or married), designation (lower or higher-level positions), and employment status (permanent, contract, or part-time) may be included in future studies. Moreover, future research studies may consider examining the impact of job satisfaction on behavioral as well as organizational outcomes such as organizational citizenship behavior, employee productivity, and so on.

\section{Acknowledgments}

The author would like to acknowledge the Central Department of Management, Tribhuvan University, Nepal for the research grant provided to this study. He is also thankful to anonymous reviewers for their valuable comments on the paper.

\section{References}

Akhtar, S. N., Hashmi, M. A., \& Naqvi, S. I. H. (2010). A comparative study of job satisfaction in public and private school teachers at secondary level. Procedia Social and Behavioral Sciences, 2, 4222-4228. https://doi.org/10.1016/j.sbspro.2010.03.668

Al-Rubaish, A. M., Rahim, S. I. A., Abumadini, M. S., \& Wosornu, L. (2011). Academic job satisfaction questionnaire: Construction and validation in Saudi Arabia. Journal of Family and Community Medicine, 18(1), 1-7. https://doi.org/10.4103/1319-1683.78630

Al-Smadi, M. S., \& Qblan, Y. M. (2015). Assessment of job satisfaction among faculty members and its relationship with some variables in Najran University. Journal of Education and Practice, 35(6), 117-123.

Amarasena, T. S. M., Ajward, A. R., \& Haque, A. K. M. A. (2015). The effects of demographic factors on job satisfaction of university faculty members in Sri Lanka. International Journal of Academic Research and Reflection, 3(4), 89-106.

Bas, T., \& Ardic, K. (2002). A comparison of job satisfaction between public and private university academicians in Turkey. METU Studies in Development, 29(1-2), 27-46.

Beyene, T., \& Gituma, M. (2017). The influence of employee demographic factors on job satisfaction: A case study of Segen Construction Company, Eritrea. African Journal of Business Management, Article Number: 0D4069E66580, 608-618. https://doi.org/10.5897/AJBM2017.8403:s[i:?

Buitendach, J. H., \& Witte, H. D. (2005). Job insecurity, extrinsic and intrinsic job satisfaction and affective organizational commitment of maintenance workers in a parastatal. South African Journal of Business Management, 36(2), 27-37. https://doi.org/10.4102/sajbm.v36i2.625

Dhammika, K. A. S. (2017). Job satisfaction, organizational commitment and OCB: An examination of three employees' behaviors in unionized work context. Kelaniya Journal of Management, 6(1), 12-31. https://doi.org/10.4038/kjm.v6i1.7524 
Din, S., Zaman, K., \& Nawaz, A. (2010). Impacts of demographic variables on job satisfaction of the academicians in universities of NWFP, Pakistan. Bulletin of Education and Research, 32(1), 53-68.

Garson, G. (2012). Testing statistical assumptions. Asheboro, USA: Statistical Associates Publications.

Gautam, T., Dik, R. V., Wanger, U., Upadhyay, N., \& Davis A. J. (2005). Organizational citizenship behavior and organizational commitment in Nepal. Asian Journal of Social Psychology, 8, 305-314. https://doi.org/ 10.1111/j.1467-839x.2005.00172.x

Goetz, K., Campbell, S. M., Broge, B., \& Dorfer, C. (2012). The impact of intrinsic and extrinsic factors on the job satisfaction of dentists. Community Dentistry and Oral Epidemiology, 40(5), 474-480. https://doi.org/10. 1111/j.1600-0528.2012.00693.x

Gray, R., Owen, D., \& Adams, C. (2010). Some theories for social accounting?: A review essay and a tentative pedagogic categorisation of theorisations around social accounting. In M. Freedman \& B. Jaggi (Eds.), Sustainability, environmental performance and disclosure: Advances in environmental accounting and management (pp. 1-54). Bingley, UK: Emerald Group Publishing. https://doi.org/10.1108/S14793598(2010)0000004005

Gunay, G. Y. (2018). Relationship between job satisfaction, organizational citizenship behavior and employee performance: Sample of Edirne Financial Office employees in Turkey. American International Journal of Contemporary Research, 8(1), 64-74.

Hackman, J. R., \& Oldham, G. R. (1975). Development of the job diagnostic survey. Journal of Applied Psychology, $60,159-170$.

Han, Y., \& Kakabadse, N. K. (2009). Job satisfaction: What is its true meaning in Greater China? Asia-Pacific Journal of Business Administration, 1(2), 155-164. https://doi.org/10.1108/17574320910989104

Herzberg. F. (1987). One more time: How do you motivate employees? Harvard Business Review, SeptemberOctober, 5-16.

Herzberg, F., Mausner, B., \& Snyderman, B. (1959). The motivation to work. Hoboken, NJ: Wiley.

Jayasena, S. D. N. S., \& Weligamage, S. S. (2016). Factors affecting job satisfaction of class III officers of Sri Lanka administrative service. Kelaniya Journal of Human Resource Management, 11(1), 17-35. https://doi.org/10.4038/kjhrm.v11i1.25

Mendoza, E. C. (2019). The mediating role of job involvement between job satisfaction and organizational commitment in a small and medium sized business enterprise. International Review of Management and Marketing, 9(5), 74-81. https://doi.org/10.32479/irmm.8355

Nunnally, J. C. (1978). Psychometric theory ( $2^{\text {nd }}$ ed.). NY: McGraw-Hill.

Parchi, A., \& Sajid, S. M. (2017). A study of job satisfaction, organizational commitment and turnover intention among public and private sector employees. Journal of Management Research, 17(3), 123-136.

Rahnavard, F., Sadati, A. K., Hemmati, S., Ebrahimzade, N., Sarikhani, Y., Heydari, S. T., \& Lankarani, K. B. (2018). The impact of environmental and demographic factors on nursing job satisfaction. Electronic Physician, 10(4), 6712-6717. https://doi.org/10.19082/6712

Ramachandran, R., \& Shanthi, K. (2020). Effect of demographic variables on job satisfaction of employees at ONGC, Karaikkal: An empirical study. International Journal of Advanced Science and Technology, 29(2), 3065-3070.

Sengupta, S. (2011). An exploratory study on job and demographic attributes affecting employee satisfaction in the Indian BPO industry. Strategic Outsourcing: An International Journal, 4(3), 248-273. https://doi.org/10.1108/17538291111185467

Shrestha, I. (2018). Influence of demographic factors on job satisfaction of financial institutions workforce of Nepal. The Journal of Business and Management, 5(1), 74-79. https://doi.org/10.3126/jbm.v5i0.27391 
Sultana, A., Sarker, M. N. I., \& Prodhan, A. S. (2017). Job satisfaction of public and private primary school teachers of Bogra district in Bangladesh. Journal of Sociology and Anthropology, 1(1), 41-46. https://doi.org/10.12691/jsa-1-1-6

Taleb, T. F. A. (2013). Job satisfaction among Jordan's kindergarten teachers: Effects of workplace conditions and demographic characteristics. Early Childhood Education Journal, 41, 143-152. https://doi.org/10.1007/s10643012-0526-9

Tarcan, M., Hikmet, N., Schooley, B., Top, M., \& Tarcan, G. Y. (2017). An analysis of the relationship between burnout, socio-demographic and workplace factors and job satisfaction among emergency department health professionals. Applied Nursing Research, 34, 40-47. https://doi.org/10.1016/j.apnr.2017.02.011

Taylor, F. W. (1911), Principals of Scientific Management. New York: Harper \& Brothers.

Tlaiss, H. A. (2013). Determinants of job satisfaction in banking sector: The case of Lebanese managers. Employee Relations, 35(4), 377-395. https://doi.org/10.1108/ER-10-2011-0064

Toker, B. (2011). Job satisfaction of academic staff: An empirical study on Turkey. Quality Assurance in Education, 19(2), 156-169. https://doi.org/10.1108/09684881111125050

Tsigilis, Zachopoulou, \& Grammatikopoulos (2006). Job satisfaction and burnout among Greek early educators: A comparison between public and private sector employees. Educational Research and Review, 1(8), 256-261.

Vaijayanthi, P., Shreenivasan, K. A., \& Roy, R. (2014). Deducting the organizational citizenship behavior dimensions and its antecedent (job satisfaction) in the Indian context. Research Journal of Applied Sciences, Engineering and Technology, 7(10), 1953-1960. https://doi.org/10.19026/ajfst.7.487

Wright, B. E., \& Davis, B. S. (2003). Job satisfaction in the public sector: The role of the work environment. American Review of Public Administration, 33(1), 70-90. https://doi.org/10.1177/0275074002250254 